\title{
GÊNERO E DIVERSIDADE NA ESCOLA: \\ EXPERIÊNCIAS SOBRE A FORMAÇÃO CONTINUADA DE PROFESSORES DA EDUCAÇÃO BÁSICA NO MUNICÍPIO DE SÃO BORJA - RS
}

GENDER AND DIVERSITY IN SCHOOL:

EXPERIENCES ON THE CONTINUED EDUCATION OF TEACHERS OF

BASIC EDUCATION IN THE MUNICIPALITY OF SÃO BORJA - RS

Ewerton da Silva Ferreira', Oneide Alessandro Silva dos Santos ${ }^{2}$ e Jaqueline Carvalho Quadrado ${ }^{3}$

RECEBIDO EM: 23/04/2017 | APROVADO EM: 03/08/2017

DOI: $10.5902 / 2317175826805$

\begin{abstract}
RESUMO
O presente artigo tem por objetivo apresentar e analisar os relatos baseados nas experiências dos bolsistas do projeto de extensão universitária da Universidade Federal do Pampa - UNIPAMPA - campus São Borja, intitulado Gênero e Diversidade na Escola, mostrando as experiências e realidades sobre ofertar um curso de formação continuada para professoras/es da educação básica pública, do sistema público de ensino, contemplando todos os níveis da educação básica: Infantil, Ensino Fundamental e Médio. A Formação aconteceu na modalidade presencial, com carga horária de 80 horas e com 50 vagas distribuídas entre a Coordenadoria Regional de Educação do Estado (CRE), a Secretaria Municipal de Educação (SMED) e o Instituto Federal. O projeto tratou de uma temática ampla sobre Educação e Direitos Humanos, tendo como eixo os Parâmetros Curriculares Nacionais, princípios teóricos e práticos, com o objetivo de refletir criticamente sobre a prática docente na escola, nos temas sobre: Gênero, Diversidade, Sexualidade e as Relações Étnico-Raciais.
\end{abstract}

Palavras-chaves: Educação. Diversidade. Gênero. Formação de professores

\footnotetext{
1 Acadêmico do sétimo semestre do curso de Ciências Humanas - Licenciatura da Universidade Federal do Pampa. Bolsista do Programa de Educação Tutorial - PET História da África. E-mail: ewertonferreira_@ hotmail.com .

2 Acadêmico do curso de Licenciatura em Dança da Universidade Federal de Santa Maria. E- mail: fio. sb.14@hotmail.com

3 Professora do curso de Serviço Social da Universidade Federal do Pampa. Coordenadora da Formação Continuada Gênero e Diversidade na Escola. E-mail: jaquelineq18@yahoo.com.br
} 
GÊNERO E DIVERSIDADE NA ESCOLA: EXPERIÊNCIAS SOBRE A FORMAÇÃO CONTINUADA DE PROFESSORES

DA EDUCAÇÃO BÁSICA NO MUNICÍPIO DE SÃO BORJA - RS

\begin{abstract}
This article aims to present and analyze the reports based in the experiences of the scholarship recipients of the extension Project offered by the Federal University of Pampa - UNIPAMPA - campus São Borja, entitled Gender and Diversity in School, showing the reality and experiences of offering a Continuing education for teachers of public education, in the public education system, covering all levels of basic education: Elementary, Middle and High School. The training took place in the classroom, with a workload of 80 hours and with 50 places distributed between the Regional Coordination of State Education, the Municipal Eduacation Secretaryand Human Rights with as its axis, the National Curricular Parameters, theoretical and practical principles, with the objetictive of reflecting critically on the teaching practice in the school, with the themes: Gender, Diversity, Sexuality and Ethnic-Racial Relations.
\end{abstract}

Keywords: Education, Diversity, Gender, Teacher training.

\title{
1 Introdução
}

Este trabalho tem por finalidade apresentar experiências dos bolsistas em um diálogo teórico e prático, através da Formação Continuada para professores e professoras da educação básica pública, intitulada Gênero e Diversidade na Escola, realizada no ano de 2015, através da extensão universitária da Universidade Federal do Pampa - UNIPAMPA - campus São Borja. A oferta Formação Continuada para professores da rede municipal, estadual e federal teve como objetivo central formar educadores e educadoras e demais profissionais que atuam nas escolas do município de São Borja nos temas diversidade, gênero, sexualidade e relações étnicas-raciais, visando provê-los com instrumentos para refletirem criticamente sobre a prática pedagógica individual e coletiva, e combaterem toda forma de discriminação no ambiente escolar.

A formação aconteceu na UNIPAMPA campus São Borja, no segundo semestre de 2015, aos sábados durante todo o dia. O projeto contou com a colaboração dos docentes da própria instituição, que através de oficinas, relatos de experiências, dinâmicas audiovisuais e musicais, aulas expositivas, visualizadas e dialogadas, ofertaram formação aos cursistas, capacitando-os e sensibilizando-os para o reconhecimento da diversidade sexual e o combate ao sexismo e a homolesbotransfobia. A forma de disseminação desses princípios dá-se, por meio de programas educacionais e intervenção na realidade escolar, aplicando valores éticos de respeito à dignidade da pessoa humana com a perspectiva de gênero, almejando a promoção dos direitos humanos e a eliminação de intolerâncias, preconceitos e discriminação.

O foco prioritário das ações de formação foram: o desenvolvimento de metodologias de enfrentamento e prevenção das diferentes formas de violações de direitos humanos, promoção do reconhecimento da diversidade e enfrentamento ao sexismo e à homlesbotransofobia, bem como a equidade de gênero no contexto escolar, assegurando espaços de discussão e troca de experiências considerando-se as especificidades locais. 
As atividades consistiram em um curso presencial de oitenta (80) horas, com conteúdo curricular que visou tratar sobre os aspectos sócio-histórico-culturais e conceituais de gênero e sexualidade; parâmetros históricos e legais; cidadania e direitos humanos LGBT; como também as experiências pedagógicas com alunos LGBT.

Desta maneira, objetivou-se contribuir para a formação de profissionais da Educação, com o intuito de produzir e estimular a produção dos alunos e alunas nas diferentes situações do cotidiano escolar, de forma articulada à proposta pedagógica e a uma concepção interacionista de aprendizagem valorizando a pluralidade no ambiente escolar. Cumprindo ,assim, o que dispõe a Lei de Diretrizes e Bases em seu

Art. $3^{\circ} \mathrm{O}$ ensino será ministrado com base nos seguintes princípios:

I - igualdade de condições para o acesso e permanência na escola;

II - liberdade de aprender, ensinar, pesquisar e divulgar a cultura, o pensamento, a arte e o saber;

III - pluralismo de ideias e de concepções pedagógicas;

IV - respeito à liberdade e apreço à tolerância;

$V$ - coexistência de instituições públicas e privadas de ensino;

VI - gratuidade do ensino público em estabelecimentos oficiais; 1 Publicada no Diário Oficial da União, Seção 1, de 23 de dezembro de 1996, p. 27833. Série 10 Legislação VII - valorização do profissional da educação escolar;

VIII - gestão democrática do ensino público, na forma desta lei e da legislação dos sistemas de ensino;

IX - garantia de padrão de qualidade;

$X$ - valorização da experiência extraescolar;

$\mathrm{XI}$ - vinculação entre a educação escolar, o trabalho e as práticas sociais.

XII - consideração com a diversidade étnico-racial.

O alcance social dessa atividade de formação foi essencial não só porque permitiu a abertura de diálogo sobre a diversidade na escola, mas porque possibilitou às professoras/es o desenvolvimento de ferramentas metodológicas para a prevenção das diferentes formas de violações dos direitos humanos no ambientes escolar.

Essa modalidade de formação continuada em gênero e diversidade na escola foi inovadora e pioneira no sistema público de educação de São Borja. Abrir a discussão sobre gênero e diversidade no ambiente escolar, nomeadamente com os professores e professoras do ensino infantil, fundamental e médio, não foi um empreendimento fácil. Sobre essa temática, há uma carga de tabus e preconceitos presente no imaginário desses educadores, a qual é difícil de depurar. Alguns passaram pela graduação sem nenhuma disciplina que abordasse a temática, e outros, mesmo atuando vários anos na educação básica, tiveram pela primeira vez a oportunidade de dialogar e trocar conhecimentos sobre diversidade no cotidiano escolar. 
GÊNERO E DIVERSIDADE NA ESCOLA: EXPERIÊNCIAS SOBRE A FORMAÇÃO CONTINUADA DE PROFESSORES

DA EDUCAÇÃO BÁSICA NO MUNICÍPIO DE SÃO BORJA - RS

O tema da sexualidade humana, por exemplo, que deveria ser amplamente discutido nas escolas para desenvolver o respeito, diálogo e diversidade, não encontra força entre as educadoras/es. A temática sobre LGBT é ainda mais refratária, havendo, inclusive, casos de homofobia, racismo, dentre outras discriminações por parte de certas educadoras/es.

\section{Reflexões sobre a formação de professores sobre Gênero, Sexualidade, Diversidade e as Relações Étnico-Raciais}

A proposta enfatizou a dimensão de que a formação de professores sobre Gênero, Sexualidade, Diversidade e as Relações Étnico-Raciais são essenciais à prática docente, pois é na escola que a diversidade se apresenta, seja nas relações de gênero entre homens e mulheres, seja na sexualidade das crianças e jovens, ou nas relações étnico-raciais diversas que formam nosso país. Destacase um trecho dos parâmetros curriculares nacionais sobre a sexualidade, que sinaliza a importância de tal discussão, dentre outras, na prática docente:

Não é apenas em portas de banheiros, muros e paredes que se inscreve a sexualidade no espaço escolar; ela "invade" a escola por meio das atitudes dos alunos em sala de aula e da convivência social entre eles. Por vezes a escola realiza o pedido, impossível de ser atendido, de que os alunos deixem sua sexualidade fora dela (PCNs - Orientação Sexual, p.77. 1998).

O lócus privilegiado, para tal discussão, é obviamente a sala de aula, onde a diversidade é múltipla, mas adversamente na maioria das vezes o(a) professor(a) não tem conhecimento sobre esses temas e nem quer ter, o que o leva a homogeneizar as relações, excluindo as diferenças e as particularidades de cada aluno, influenciando seu aprendizado e sua reflexão sobre esses temas para toda a vida em sociedade, como também no seu exercício da cidadania. Nesse sentido, é imprescindível (re)pensar a prática pedagógica cotidianamente, por um viés crítico e reflexivo. Conforme escreveu FREIRE (p.37) "a prática preconceituosa de raça, de classe, de gênero ofende a substantividade do ser humano e nega radicalmente a democracia", por isso e muito mais, é necessária a reflexão crítica da própria prática docente.

Se a escola torna-se um lugar distante da realidade vivida, a cidade de São Borja também não ocupava outrora uma localização privilegiada no espaço geográfico, em termos de centros culturais e universitários. A distância geográfica e o fechamento do curso de formação de professores (Pedagogia) em outra universidade dificultou a Formação Continuada de professores, mas é através do Programa de Apoio a Planos de Reestruturação e Expansão das Universidades Federais (REUNI) que a Universidade Federal do Pampa se instalou em dez cidades. Sendo elas: cinco fronteiriças e cinco interioranas, onde atualmente conta com mais de sessenta (64) cursos de graduação, trinta e duas 
(32) especializações, dez (10) mestrados e dois (2) doutorados que oportuniza os profissionais da Fronteira Oeste e Fronteira Sul a possibilidade de uma formação continuada, pública e de qualidade.

É na tentativa de sanar o déficit na formação dos profissionais da educação que atuam na rede pública que a Formação Continuada sobre Gênero e Diversidade na Escola vem proporcionar a discussão de temas que, por vezes, não fazem parte dos currículos dos cursos de licenciatura no Brasil, todavia invadem as salas de aula.

O estabelecimento de currículos (escolares ou não) diz respeito a um complexo processo de decisões políticas em que são privilegiados certos conhecimentos, enquanto outros não são considerados como "dignos" de integrar os processos de educacionais. No campo de gênero e da sexualidade, certas coisas são adequadas para meninos, mas não são para meninas, e viceversa. Vale dizer, então, que o campo da educação se defronta com grandes debates que envolvem o que estudar, como estudar, quando estudar, e mais ainda quem são os agentes autorizados a dirigir este processo de ensino, a saber, os professores e professoras. (LOURO. 2011. p.48)

A UNIPAMPA adota o conceito de extensão universitária, definido pelo Fórum de Pró-Reitores de Extensão das Instituições Públicas de Educação Superior Brasileiras (FORPROEX, 2010):

"A Extensão Universitária, sob o princípio constitucional da indissociabilidade entre ensino, pesquisa e extensão, é um processo interdisciplinar educativo, cultural, científico e político que promove a interação transformadora entre universidade e outros setores da sociedade".

O desenvolvimento das oficinas em parceria com as escolas públicas demonstra a importância da função social das universidades públicas na sociedade, em especial, nas regiões interioranas e conservadoras. Além disso, expande as discussões pautadas nos temas transversais preconizados nos Parâmetros Curriculares Nacionais sobre Orientação Sexual (PCN - 1997), com intuito de formar uma rede com escolas e desta forma contribuir com a ampliação do diálogo entre universidade e comunidade externa, buscando assim auxiliar na inclusão de novos temas no currículo escolar voltados a realidades locais, bem como promover a diversidade, rompendo com violências de gênero nas escolas.

O projeto de Extensão cumpre a tríade da universidade - pesquisa, ensino e extensão -, pois além de difundir o conhecimento produzido no meio acadêmico, possibilita que professores e professoras possam realizar um diálogo teórico prático entre docentes da UNIPAMPA e da rede de Educação Básica sobre os desafios, os anseios, as dificuldades de se abordar a diversidade na escola, conforme os parâmetros curriculares nacionais (p. 83), os quais determinam 
GÊNERO E DIVERSIDADE NA ESCOLA: EXPERIÊNCIAS SOBRE A FORMAÇÃO CONTINUADA DE PROFESSORES

DA EDUCAÇÃO BÁSICA NO MUNICÍPIO DE SÃO BORJA - RS

que "De forma diferente, cabe à escola abordar os diversos pontos de vista, valores e crenças existentes na sociedade, para auxiliar o aluno a encontrar um ponto de auto referência por meio da reflexão." Ao abordar essa reflexão, se enfatiza as diversidades, como também se referencia às relações de gênero, de sexualidade, da própria diversidade dos alunos e alunas no cotidiano escolar e das relações étnicas-raciais.

\section{Relatos dos bolsistas e realidades apresentadas na Formação}

A abordagem dos temas gênero, sexualidade e orientação incomoda as estruturas tradicionais das escolas e setores conservadores da sociedade. Em 2015 , as discussões sobre os temas nos planos estaduais, municipais e nacional reuniram centenas de pessoas nas casas legislativas e dividiram opiniões. De um lado, educadores, militantes e pessoas LGBTTIQ defendendo a abordagem dos temas, por compreenderem a importância da inclusão no currículo escolar, e de outro lado, religiosos, educadores conservadores e instituições levantando bandeiras contrárias.

A pressão por parte dos setores mais conservadores fez com os que temas fossem retirados da maioria dos planos estaduais e municipais, além do nacional. No entanto, a exclusão não retira as cenas de violência de gênero e casos de homolesbotransfobia do contexto escolar. É preciso pensar qual o papel da escola em relação aos alunos e alunas que sofrem e são excluídos diariamente pelo preconceito e, sobretudo, refletir sobre o papel dos educadores na formação desses indivíduos que historicamente são excluídos da sociedade. Nesse sentido, não podemos pensar em uma prática escolar neutra e sem problematizar as questões de formação dos educandos enquanto cidadãos críticos e conscientes. De acordo com Silva:

Quais grupos sociais estão incluídos - e de que forma estão incluídos - e quais grupos sociais estão excluídos? Como resultado dessas divisões, dessas inclusões e exclusões, que divisões sociais - de gênero, raça, classe - são reproduzidas ou reforçadas? E, naturalmente, a pergunta mais importante a ser feita é: qual nosso papel, como educadores e educadoras, nesses processos de divisão e, portanto de relações de poder? (SILVA, 1995, p.197)

É preciso compreender que esses grupos sociais foram historicamente padronizados na norma branca, heterossexual, classe média e cristã. Além disso, por muito tempo eles não tiveram acesso ao ingresso na escola pública brasileira, visto que até a democratização efetiva, que aconteceu a partir da Constituição Federal de 1988, apenas determinados grupos gozavam desse acesso. 
Em 1998, foi aprovada a Constituição Federal, que em relação à educação, no seu Art. 205, a institui como sendo "direito de todos e dever do Estado e da família, será promovida e incentivada com a colaboração da sociedade, visando ao pleno desenvolvimento da pessoa, seu preparo para o exercício da cidadania, e sua qualificação para o trabalho". Estabeleceu-se, ainda, no Art.206, que o ensino será ministrado com base nos seguintes princípios: "I- igualdade de condições para o acesso e a permanência na escola [...] IV - gratuidade do ensino público em estabelecimentos oficiais". (ROSA, LOPES, CARBELLO, 2015, p.169).

No entanto, a chegada de novos sujeitos à educação básica não efetivou essa democratização em seus currículos, que permaneceram valorizando conteúdos voltados ao padrão que já estava no ambiente escolar, bem como a pouca formação crítica, emancipada e com o preparo para cidadania, buscando apenas a formação para o mercado de trabalho. Portanto, é preciso compreender que "fundamentalmente a escola precisa fazer sentido na vida do aluno, e fazer diferença na sua vida" (SEFFNER, 2011, p.108).

O diálogo e a reflexão são elementos essenciais para o processo de construção de conhecimento na formação, em que as experiências vividas são partilhadas e amparadas às teorias. Os (as) professores e professoras cursistas nos encontros partilharam suas experiências com a abordagem dos temas em sala de aula. Desses partilhamentos, destacaremos alguns relatos que demostraram a necessidade de espaços como este para a redução dos casos de homelesbotransfobia no ambiente escolar. Em um dos encontros, a aula foi ministrada por um psicólogo e uma assistente social, pois dentre seus objetivos estava a necessidade de apoio aos alunos e alunas que estão no processo de descobrimento/aceitação de sua sexualidade. Para a surpresa dos que estavam presente, uma das participantes começou a explanar a situação que acontecia dentro de sua casa, através da hipótese de seu filho ser gay e da não "aceitação" da sexualidade de seu filho. A situação tomou uma proporção grande, e foi preciso combinar uma conversa depois da aula pelo fato da professora/mãe começar a chorar na sala. Outro caso foi de uma professora que mencionou o fato da homossexualidade ser algo que contraria as leis de Deus, e havia necessidade dos alunos e alunas buscarem auxílio psicológico para tentarem ser "curados" desse desvio que acontece com eles. Nesse sentido, ficou nítido que a formação de professores é importantíssima, pois se existem dúvidas de como lidar com essa questão dentro do espaço doméstico, subentende-se que no ambiente escolar essa prática é inexistente ou até mesmo equivocada, isto é, a partir de princípios e valores pessoais, religiosos dentre outros, que não partem de um conhecimento científico.

Portanto, acreditamos que através da formação com diversas oficinas didáticas, documentários e materiais de apoio, os professores e professoras podem reconstruir ideias, ideais e a própria prática pedagógica que os ajuda a discernir sobre as diversas realidades apresentadas em sala de aula.Essa 
GÊNERO E DIVERSIDADE NA ESCOLA: EXPERIÊNCIAS SOBRE A FORMAÇÃO CONTINUADA DE PROFESSORES

DA EDUCAÇÃO BÁSICA NO MUNICÍPIO DE SÃO BORJA - RS

formação também ajuda como entender a particularidade de cada aluno no processo educativo e de formação, enquanto futuros cidadãos, como assegura BIANCO (2009 apud Regattieri, Castro, 2013, p. 9):

O aluno como centro, adequando o ensino a suas características e necessidades, partindo do que é, sabe e sente - mediatizado por seu ambiente sociocultural e promovendo o desenvolvimento de suas capacidades, potencialidades e interesses.

É também um momento ímpar para nós, licenciando -bolsistas, para podermos perpassar por essa experiência e conferir as realidades e discursos dos professores que já trabalham com crianças e jovens. Pois, no futuro teremos que encarar esse tipo de realidade na grande área de ciências humanas, assim certamente, já teremos uma grande bagagem para a futura prática pedagógica.

Neste processo de formação continuada de professores da educação básica constatou-se, através do curso de extensão, a baixa adesão pelos professores, muitos pelas dificuldades do cotidiano de sua profissão, outros pela desmotivação e desvalorização de sua profissão, também pela carga horária que os professores exercem chegando a 60 horas semanais, o que os leva a exaustão aos finais de semana, que por sua vez os deixam desmotivados para frequentar um curso de formação. No entanto, fica evidenciada a desmotivação ou desinteresse do professor ligada a sua competência, pois como cita DEMO:

Disto segue que o professor precisa, com absoluta ênfase, de oportunidade de recuperar a competência, de preferência a cada semestre, por meio de cursos longos (pelo menos 80 horas), nos quais se possa pesquisar, contraler, elaborar, discutir de modo argumentado, (re) fazer propostas e contrapropostas. (DEMO, 2000, p. 61.)

As oportunidades de formações atualmente são mais amplas devido aos processos de interiorização das universidades, por meio dos seus projetos de extensão, como este que por ora descreve-se. Deste modo, ressalta-se que o interesse em qualificação profissional está ligado ao processo de refazerse enquanto educador, na visão de DEMO (2001), na busca constante da sua competência, perpassando também processos de formação dos professores e questões sociais ligadas à valorização dos profissionais e sua cidadania. Acompetência do professor está em intermédio ao seu desempenho, por isso a necessidade de formações continuadas nos temas que ainda, infelizmente, são considerados "tabus" na sociedade contemporânea, tais como: gênero, diversidade, sexualidade e as relações étnico-raciais.

Notou-se, nesta vivência parcial do projeto de extensão, o difícil diálogo entre os entes públicos, principalmente na esfera municipal e estadual, para a participação efetiva dos professores que atuam na rede de ensino público .Esse fato foi 
constatado no processo de abertura de vagas disponibilizadas a rede pública de ensino. Ofertou-se cinquenta (50) vagas, e somente trinta (30) inscritos, sendo que na continuidade do curso, no segundo semestre de 2015, apenas doze (12) professores (as) continuaram a formação. $O$ curso teve ampla divulgação junto às entidades parceiras de educação, sendo que as mesmas concordaram em facilitar a ofertado curso de formação, portanto, vale refletir sobre a baixa adesão à formação.

Entre os problemas referidos pelos participantes que desistiram do curso estão: a falta de tempo nos finais de semana; aulas de reposição nos sábados, nas escolas que os participantes atuam, devido às paralisações da categoria; o desmotivo; problemas familiares; não ter vantagens em fazer uma formação continuada. O levantamento foi realizado por meio de contatos telefônicos a cada um dos participantes, com a finalidade de averiguar os motivos que os levaram a desistir do curso.

Embora a baixa adesão seja um fato no decorrer do curso, é válida a experiência que torna o curso mais qualitativo do que quantitativo, para os cursistas, bem como para os professores da Unipampa e bolsistas - licenciandos, que desta forma remetem a reflexão para, além da temática do curso, a formação continuada de professores na nossa região da fronteira oeste, e os retratos da realidade desses professores da educação básica, que analisamos anteriormente.

\section{Reflexões teóricas sobre a prática pedagógica}

Volta-se a permear o campo reflexivo que o curso propôs aos professores cursistas, ampliando o pensar para novas possibilidades e identidades, antes não reconhecidas ou negadas no ambiente escolar. Este é o caso da sexualidade, das relações de gênero, cor e raça que entrelaçam a vida dos alunos e professores na escola, e tomam conta das suas vivências em sociedade. Para Louro:

\footnotetext{
"Estamos no meio de uma disputa política em torno das identidades sexuais e de gênero - é o que parecem indicar as situações aqui analisadas. Esta disputa é travada, cotidianamente, em múltiplas instâncias sociais e, no currículo. De um lado, o discurso hegemônico remete à norma branca, masculina, heterossexual e cristã; de outro lado, discursos plurais, provenientes de grupos sociais não hegemônicos lutam para se fazer ouvir, rompendo o silenciamento a que foram historicamente submetidos. A escola e o currículo estão imersos em tudo isto, fazem parte deste jogo, portanto tem a possibilidade de alterar a configuração da luta". (2000, p.56)
}

Então, se percebe que o ambiente da escola é feito de relações entre indivíduos em uma determinada sociedade e localidade, que a partir de gêneros masculinos e femininos, criam suas formas culturais de relacionar-se uns com os outros e com os professores, também criando ou construindo suas formas de definição de gênero, "normalidade" e heterossexualidade, que são frutos historicamente 
GÊNERO E DIVERSIDADE NA ESCOLA: EXPERIÊNCIAS SOBRE A FORMAÇÃO CONTINUADA DE PROFESSORES

DA EDUCAÇÃO BÁSICA NO MUNICÍPIO DE SÃO BORJA - RS

criados pelo homem, tornando a sociedade disciplinada e controlada por instituições e dispositivos como a escola, que é nosso foco de estudo.Foucault (1988, 1987) escreveu, em suas obras clássicas, sobre a sexualidade enquanto um "dispositivo histórico" e que a sociedade produz sujeitos "úteis e pacíficos".

É neste momento que a escola, enquanto formadora de conceitos e conhecimentos, pode ser um espaço de dissolução desses temas históricos que emergem em sala pela diversidade presente, seja pelas culturas, ou pelo grito dos excluídos que clamam a inclusão nos espaços educativos. O papel desse curso de formação continuada é ,justamente, o de dar espaço ao excluído ou aos excluídos do sistema heteronormativo, e dar inclusão a estes que vivem marginalizados socialmente, bem como dar visibilidade a uma realidade que é invisibilizada muitas vezes pela escola, pela família, pelos professores e pela sociedade de um modo geral.

Por isso, é necessário que os professores da educação básica adaptem seus currículos e disciplinas de acordo com as realidades presentes em sala de aula, considerando as particularidades de cada aluno, enquanto um ser social e político que reproduz aquilo que a escola o passa. Neste sentido, os temas transversais e interdisciplinares entram em cena, para poderem atravessar a realidade da sala de aula e poderem discutir temas emergentes da sociedade que são muitas vezes são ignorados. Conforme Yus:

O atual discurso da pedagogia crítica e de resistência também encontra nas temáticas transversais a oportunidade de refletir sobre muitas de nossas inércias profissionais, ir além do sentido acadêmico das culturas que se transmitem nas aulas e abordar o sentido social do ensino para, finalmente, contribuir para que os indivíduos sejam autônomos, críticos e solidários, respeitosos consigo mesmos e com os demais e com o próprio meio; enfim para que a escola contribua para a criação de uma sociedade mais justa, igualitária e solidária ou que, ao menos, contrabalance os efeitos perniciosos que provoca o desenvolvimento em sociedades neoliberais como a nossa. (1998, p. 29 - 30).

Os temas transversais e interdisciplinares podem dar conta disso, se o professor, junto com sua competência, refletir sobre sua prática, podendo formar alunos que promovam o respeito sobre as diferenças e as diversidades da sociedade. Isto é, o que o projeto de extensão proporcionou aos cursistas/ professores foi a reflexão crítica da prática para ir além de suas disciplinas e conteúdos de forma interdisciplinar e dialógica.

É necessário potencializar o aprendizado social dos alunos, além do científico, e a família e a escola devem ser espaços para tal. Por isso enfatizamos a relação da escola e família no aprendizado e desenvolvimento, sempre analisando os contextos sociais e de interação dos indivíduos em sociedade, pois segundo Vygotsky (2007, p. 94) "o aprendizado começa muito antes de a criança frequentar a escola". Ou seja, de acordo com Vygotsky, grande escritor da psicologia da 
educação, define-se o aprendizado como algo interativo social, e com isso a importância de relacionar os conteúdos curriculares com as realidades sociais.

A família e a escola são espaços de construção de pessoas através do processo educativo que formam cidadãos para viverem em sociedade. Vale citar, portanto, a LDB, Lei de Diretrizes e Bases da Educação Nacional de 1996, que afirma o dever da educação tanto da família como do Estado - Escola, e o exercício da cidadania, conforme Art. $2^{\circ}$ da LDB:

A educação, dever da família e do Estado, inspirada nos princípios de liberdade e nos ideais de solidariedade humana, tem por finalidade o pleno desenvolvimento do educando, seu preparo para o exercício da cidadania e sua qualificação para o trabalho. (p.11).

As nossas constituições da educação também devem guiar a prática pedagógica, e com isso ajudar o professor a potencializar seu aluno para sua cidadania. Por isso, é sempre necessário citar e revalidar as legislações brasileiras da educação como a LDB e os PCNs e refletir sobre elas, se de fato estão promovendo aquilo que descrevem e afirmam. O curso de extensão tem esse gancho com as legislações para atribuir aos professores aspectos legais sobre a prática pedagógica, nos temas sobre a diversidade, a sexualidade, as relações de gênero e de etnias, para fomentar o discernimento sobre todas as questões sociais e políticas que norteiam a prática docente.

\section{Considerações finais}

Considerou-se, com esta análise sobre a formação continuada de professores (as) da educação básica entre elementos teóricos e práticos, que a capacitação desses profissionais da educação é essencial ao processo de atualização do conhecimento entre ensino e aprendizagem, tanto pela constante busca de sua própria competência, quanto pela reflexão crítica da prática pedagógica. Observou-se que os professores (as) que participaram do curso puderam refletir sobre sua prática, e assim reconstruíram novos conceitos e conhecimentos sobre a diversidade que está presente nas realidades educacionais em que estão inseridos, servindo como aporte para eliminar várias formas de preconceitos escolares.

No entanto, constatou-se também problemas no decorrer do curso, como a baixa adesão ao projeto, sendo poucos professores (as) que participaram, e no difícil diálogo entre os entes públicos, como a $35^{\circ}$ Coordenadoria Regional de Educação e Secretaria Municipal de Educação de São Borja, que dificultaram a abrangência do curso entre fatores externos. Também entre os entraves do curso está o fato de que muitos professores (as) matriculados posteriormente desistiram do curso, por motivos profissionais e pessoais, entre os quais muitos profissionais alegavam que tinham aulas aos sábados devidos paralisações da categoria durante o ano. 
GÊNERO E DIVERSIDADE NA ESCOLA: EXPERIÊNCIAS SOBRE A FORMAÇÃO CONTINUADA DE PROFESSORES

DA EDUCAÇÃO BÁSICA NO MUNICÍPIO DE SÃO BORJA - RS

Analisou-se também que muitos professores (as) apresentaram-se desmotivados a participar de cursos de formação continuada, já que não acrescentava em seu bônus salarial ou progressão de carreira. Já alguns professores (as) demonstraram extremo interesse em participar do curso em busca de conhecimento e de aprofundamento pedagógico, além de expor suas vivências e realidades escolares. Assim, notou-se o diálogo entre os professores da Unipampa com os professores (as) cursistas, que puderam aspirar aos anseios dos cursistas, e problematizá-los repensando a prática pedagógica.

Com isso, constata-se de muita importância este curso e, além disso, a necessidade de enfatizar espaços de ensino e aprendizagem entre professores, pois assim, estão espontaneamente tendo acesso ao conhecimento e as múltiplas experiências do cotidiano escolar. $O$ diálogo é o elemento crucial para a produção e construção de novos conceitos e reflexões neste curso de formação continuada de professores da educação básica, que possibilitou aos cursistas refletir criticamente sobre sua prática pedagógica de forma concisa e coesa.

Considera-se todas essas experiências enriquecedoras para nós, futuros professores atualmente em formação, pois possibilitou conhecermos muitas realidades e relatos de professores (as) que já atuam na rede pública básica, também seus anseios e medos de abordar ou trabalhar a diversidade dentro da sala de aula, que é tão explícita. Desta maneira, enxergamos a sala de aula com uma nova visão que vai além de meros alunos, mas de pessoas humanas que possuem uma vida por trás de sua aparência, e que a escola também deve ser acolhedora das diferenças e das diversas manifestações sociais, culturais, de identidades, de cor, de religião, de sexualidade, de gênero, pois é na escola que acontece o encontro de tudo que posteriormente estará na sociedade em conflito ou harmonia.

O que nos tranquiliza é a consciência de que a "Formação Continuada Gênero e Diversidade na Escola" têm enormes desafios pela frente. Um dos caminhos possíveis até a cidadania de fato é a incorporação do debate Gênero e Diversidade na formação de professores/as que trabalham com crianças e jovens, com vistas a um mundo sem intolerância, mais plural e democrático. Formar educadores/as é apenas o primeiro passo. 


\section{Referências}

BRASIL. Lei de Diretrizes e Bases da Educação Nacional. 1996.

Parâmetros Curriculares Nacionais. Orientação Sexual. 1997.

BIANCO, Rosa et al. Educação de qualidade para todos: um assunto de direitos humanos. Brasília: UNESCO, OREALC, 2009. p. 52.

DEMO, Pedro. Educar pela pesquisa. 4. ed. São Paulo: Autores associados, 2000.

FREIRE, Paulo. Pedagogia da autonomia: saberes necessários à prática educativa. 46. ed. Rio de Janeiro: Paz e Terra, 2013.

Fórum de pró-reitores de extensão das instituições públicas de educação superior brasileiras (FORPROEX). Política nacional de extensão universitária. Gráfica da UFRGS. Porto Alegre, RS, 2012 (coleção extensão universitária; v. 7).

FOUCAULT, Michel. Vigiar e punir: nascimento da prisão. Petrópolis: Vozes, 1987.

A história da sexualidade. A vontade de saber. 11. ed. Rio de Janeiro: Graal, 1988.

LOURO, Guacira Lopes. Currículo, Gênero e Sexualidade. Portugal: Porto Editora, 2000.

REGATTIERI, Marilza; CASTRO, Jane Margareth. Currículo integrado para o Ensino Médio: das normas à prática transformadora. Brasília: UNESCO, 2013.

ROSA, Chaiane; LOPES Nataliza; CARBELLO Sandra. Expansão, democratização e a qualidade da educação básica no Brasil. Poíesis Pedagógica, Catalão-GO, v.13, n.1, p. 162-179, jan/jun. 2015

SEFFNER, Fernando. Escola para todos: mesmo para aqueles que manifestam diferenças em sexo e gênero In. Corpos, gêneros, sexualidades e relações étnico-raciais na educação. Uruguaiana - RS: UNIPAMPA, 2011.

SILVA, Tomaz Tadeu. Currículo e identidade Social: territórios contestados. In. SILVA, Tomaz Tadeu. (Org). Alienígenas na sala de aula: uma introdução aos estudos culturais em educação. Petrópolis: Vozes, 1995. P.190-207.

VIGOTSKY, Lev Semenovich. A formação social da mente: o desenvolvimento dos processos psicológicos superiores. 7. ed. São Paulo: Martins Fontes, 2007.

YUS, Rafael. Temas transversais: Em busca de uma nova escola. Porto Alegre: ArtMed, 1998. 